\title{
Duas Décadas de Química Inorgânica em Aveiro: Uma visão pessoal
}

\section{Introdução}

Apresenta-se neste texto uma visão essencialmente pessoal "à vol d'oiseau" do desenvolvimento da investigação em Química Inorgânica, no Departamento de Química da Universidade de Aveiro, desde o início, pouco tempo após a criação da Universidade, até finais dos anos noventa. Durante cerca de duas décadas a liderança do grupo de Química Inorgânica esteve nas mãos do Professor Júlio Pedrosa, que imprimiu aos trabalhos de investigação a orientação que conduziu ao desenvolvimento actual de um forte centro de investigação activo em Ciências de Materiais, onde a componente de Química Inorgânica tem um papel relevante.

0 relato aqui apresentado não tem a preocupação de ser exaustivo (seria impossivel no âmbito de um artigo deste tipo) ou de seguir rigidamente qualquer ordem cronológica. Procura-se, antes, identificar os temas dos primeiros estudos realizados e seguir a sua evolução até alguns dos trabalhos actualmente em curso. Iniciado num tempo em que a actividade laboratorial de investigação científica nas universidades portuguesas era realizada quase exclusivamente pelos seus docentes (assistentes e assistentes estagiários), relaciona-se, necessariamente, com o início e progresso da carreira de alguns dos actuais Professores da Universidade de Aveiro. A informação apresentada é com certeza parcelar, sem que isso implique que os factos ou nomes omitidos sejam menos relevantes.

\section{O início da Química Inorgânica em Aveiro}

Difícil será perceber ou avaliar agora o que pensaria um recém-doutorado ao chegar à Universidade de Aveiro nos anos de 1974-1979. A sua frente estava a estimulante tarefa de organizar aulas e investigação de uma "instituição" (o Departamento de Química, DQUA) a partir de quase nada. É "como caderno novo, quando a gente o principia", como diz o poeta [1]. O desafio e o entusiasmo só poderão agora ser recordados, não serão repetidos.

No início, portanto, não havia balizas. Haveria ideias directoras, sem dúvida. Os primeiros projectos surgiram norteados pelo interesse despertado pelas Ciências do Ambiente, que conduziram à abertura de um curso em Ciências do Ambiente (em 1975), quase meia década antes de haver uma Licenciatura em Química em Aveiro. Assim, em 1982, todo o Departamento se juntou para formar um Centro do INIC a que se chamou "Centro de Química do Meio Aquático" (CEQMA). O INIC, Instituto Nacional de Investigação Científica, era, à época, a entidade financiadora da investigação científica nacional, convém lembrar para benefício dos mais novos. Quatro doutorados, quatro linhas de investigação, naturalmente. Para lançar a semente dos estudos em Química Inorgânica estava o então Professor Auxiliar Júlio Pedrosa (JP).

Esta minha crónica inicia-se, mais propriamente, em Outubro de 1979. O Departamento de Química mudara-se para edificio próprio, um "luxo". Três laboratórios de aulas e dois de investigação, bem separados, gabinetes ocupados, cada um, por duas pessoas (mais tarde alguns acomodariam até quatro docentes), alguns instrumentos e o primeiro "estudante" de doutoramento, ou seja, eu. Como meus orientadores, JP e o Professor Vitor Gil (VG). Tema: estudo de compostos de coordenação de molibdénio e tungsténio com ligandos naturais em solução. Este tema surgia naturalmente dos interesses científicos de JP, com um doutoramento em Química de Coordenação, e de VG, que se debruçava sobre o estudo de complexos metálicos por espectroscopia de Ressonância Magnética Nuclear. Trocado por miúdos, o meu trabalho de doutoramento consistiu essencialmente no estudo de complexos derivados de aminoácidos e hidroxiácidos com Mo(VI) e W(VI), por meio de técnicas espectroscópicas (RMN, UV, dicroísmo circular), envolvendo, nomeadamente, caracterização das espécies formadas em solução aquosa, determinação de constantes de equilíbrio e síntese de alguns sólidos. Claro que o Departamento de Química de Aveiro não tinha espectrómetro de RMN que permitisse este tipo de estudos. A investigação desenvolveu-se, então, apoiada no equipamento existente em Coimbra, de $100 \mathrm{MHz}$, da responsabilidade de VG, e no de Lisboa, instalado no IST ( $300 \mathrm{MHz}$ ), ao cuidado do Prof. António Xavier. Os espectros de dicroísmo circular faziam-se no University College, em Cardiff, UK, com o apoio dos Professores R. Gillard e P. Williams.

\footnotetext{
* Departamento de Quimica, Universidade de Aveiro, 3810-193 Aveiro, ana@dq.ua.pt
} 
figura 1 Estrutura molecular do complexo $\left.\left[\mathrm{Mo}_{4} \mathrm{O}_{12} \text { (picOH) }\right]_{2}\right]^{2}, \mathrm{HpicOH}=$ ácido $3-$ hidroxipicolínico, $\mathrm{C}_{6} \mathrm{H}_{5} \mathrm{NO}_{3}$.

0 molibdénio e tungsténio são elementos de transição do grupo 6. A sua química de coordenação, extensa e variada, foi um tema aliciante. Qualquer um destes elementos pode ocorrer numa larga gama de estados de oxidação (de $-2 a+6)$, em geometrias de coordenação variadas. É difícil abarcar de uma maneira global o comportamento químico destes elementos, tal a sua diversidade [2]. Os estudiosos dos estados de oxidação mais elevados $(+4 a+6)$, com grande predominância de compostos com oxigénio e enxofre, poderão não conhecer senão imperfeitamente a química dos estados de oxidação mais baixos. A atracção por estes elementos foi tão intensa, no meu caso, que dura até hoje.

No estado de oxidação +6 , molibdénio e tungsténio ocorrem em soluçōes aquosas alcalinas na forma de aniōes $\mathrm{MO}_{4}{ }^{2-}$, $M=M o, W$, que originam espécies condensadas aniónicas por acidificação. A $\mathrm{pH}$ suficientemente baixo dá-se a preci-

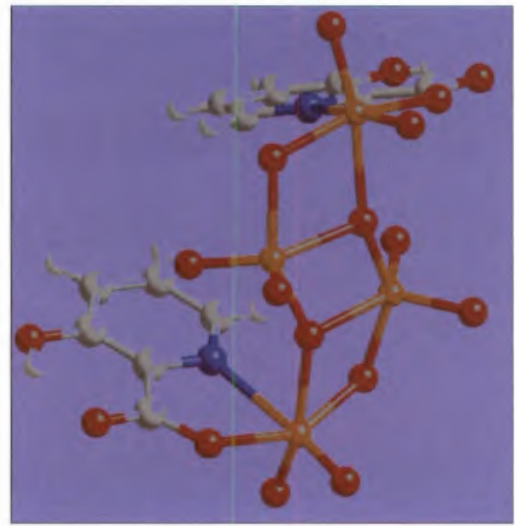

pitação de óxidos hidratados, um comportamento diferente do da maioria dos metais de transição, que ocorrem em solução aquosa na forma catiónica e originam óxidos e hidróxidos por adição de base. Apesar da sua carga, o molibdato e o tungstato reagem facilmente com ligandos orgânicos, mesmo carregados negativamente, formando complexos estáveis. 0 meu estudo ligava-se ao facto de haver pouca informação sobre a interacção do $\mathrm{Mo}(\mathrm{VI})$ com moléculas naturais pequenas, as quais poderiam estar associadas ao seu transporte em águas naturais. $\mathrm{O}$ interesse pela identificação e caracterização das espécies químicas em soluções aquosas justificava-se pela relevância ambiental e biológica destas. 0 estudo de complexos destes metais encontra ainda hoje razões muito variadas que o justifiquem, relacionadas, por exemplo, com a sua importância bioquímica (mais no caso do Mo que do W), aplicações em catálise, desenvolvimento de materiais, etc. Outros investigadores ( $\left.\mathrm{HN}, I \mathrm{G}, \mathrm{VF}^{\star}\right)$ con- tinuam hoje, em Aveiro, interessados em complexos de molibdénio, como o representado na figura 1 [3].

A segunda pessoa a preparar o seu doutoramento na área da Química Inorgânica em Aveiro foi Clara Magalhães (CM), que iniciou os trabalhos em 1982, sob a orientação de JP e P. Williams. O seu tema versava a química de formação de minerais secundários contendo arsenatos e fosfatos. Abria-se assim uma nova área de estudo, relacionada com a compreensão da termodinâmica de formação e solubilização de minerais em meios aquosos naturais (figura 2). Enquanto que a formação da maior parte dos minerais primários (quartzo e outros óxidos, silicatos, sulfuretos) é de reprodução laboratorial difícil, devido às condições de pressão, temperatura e complexidade dos meios onde se desenvolvem, tal não acontece para muitos minerais secundários, formados por alteração química a partir dos primários e de outros secundários. Na sua tese de doutoramento, CM estudava um largo conjunto destes minerais, elaborando, a partir de estudos de solubilidade, diagramas de equilibrio de fases como o representado na figura 3 [4].

O estudo de minerais teve continuação no seguimento deste trabalho de doutoramento, prolongando-se até aos dias de hoje. Os projectos mais recentes orientaram-se para o controlo da dispersão de poluentes por meio da formação de minerais secundários pouco solúveis. Como exemplo pode-se citar o uso da precipitação de arsenatos de chum-

figura 2 Áreas de investigação desenvolvidas pelo grupo de Quimica Inorgânica do DQUA

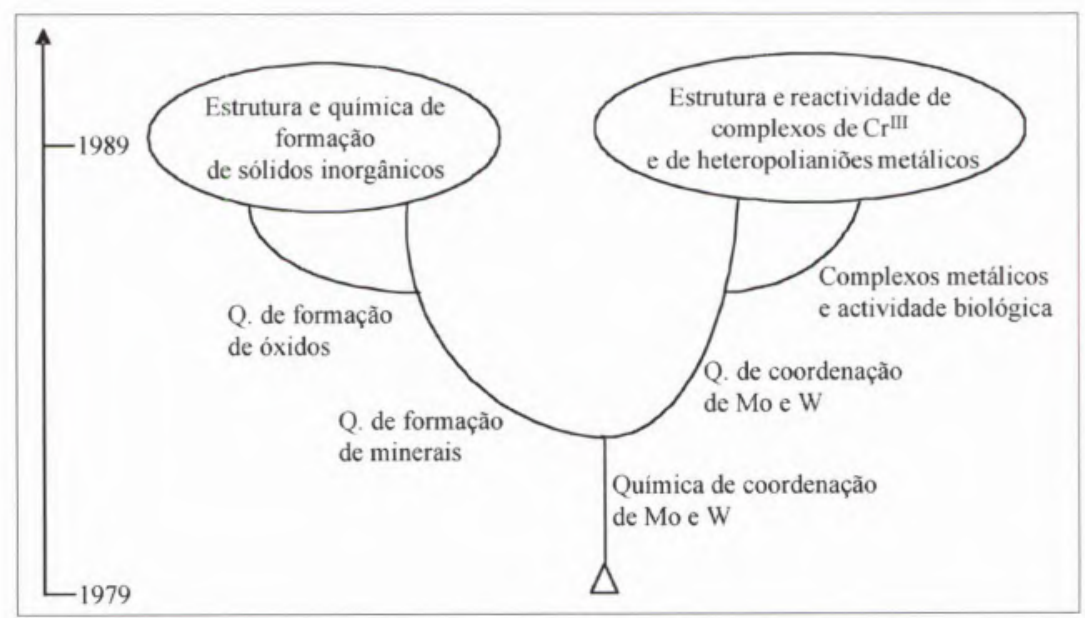




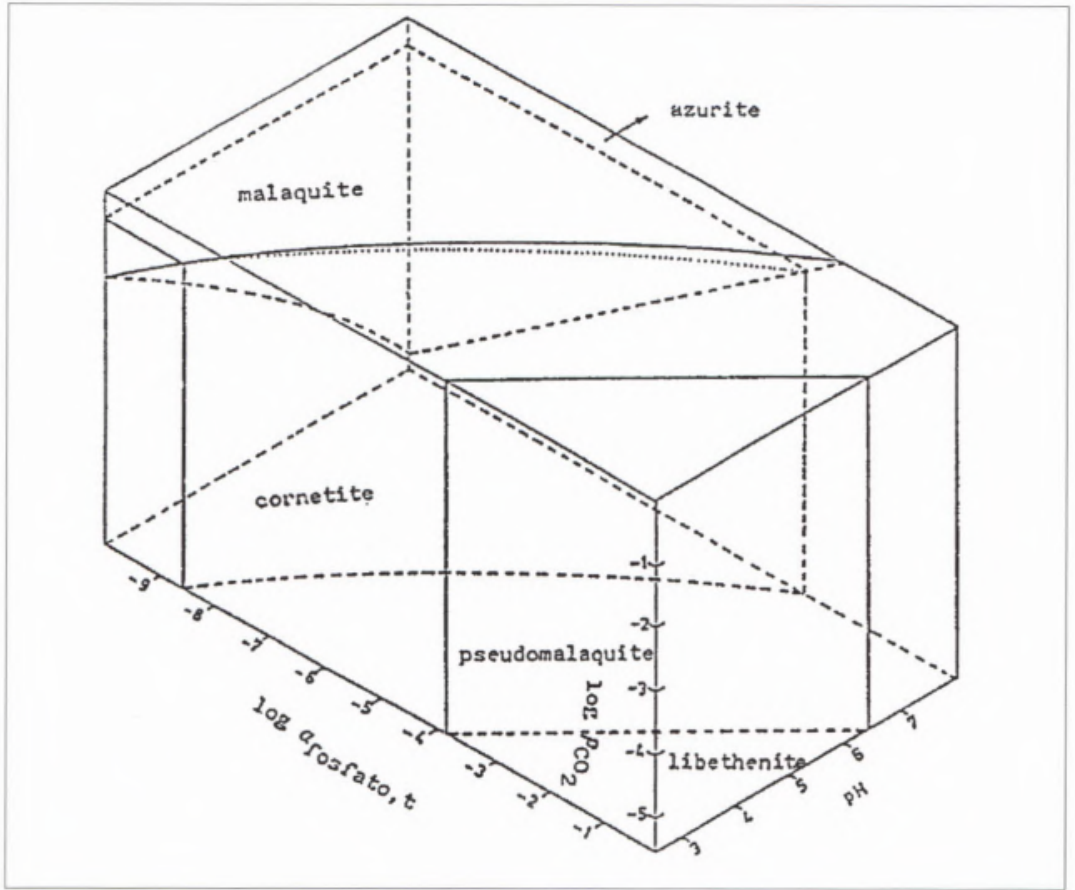

bo como processo de imobilização de $\mathrm{Pb}$ e As [5]. Introduziu-se, entretanto, o estudo de biomateriais como nova área de investigação. Esta centra-se no estudo de hidroxiapatites substituídas, nomeadamente nas condições de precipitação e dissolução destas [6].

\section{A primeira viragem}

Em meados dos anos oitenta o grupo de investigadores de Química Inorgânica estava já envolvido num conjunto alargado de actividades bem programadas. Consul- tando, por exemplo, um relatório de progresso do CEQMA referente a 1987, encontramos listados sete docentes/investigadores, liderados por JP, e quatro projectos, dos quais dois no âmbito da química de coordenação e dois no campo do estudo da formação de minerais e óxidos metálicos. Estes projectos foram posteriormente agrupados em dois temas: "Estrutura e reactividade de compostos de coordenação de $\mathrm{Cr}$ (III) e de heteropolianiões metálicos" e "Estrutura e química de formação de sólidos inorgânicos" (figura 2). Os anos dos finais da década de oiten- figura 3 Diagrama de campos de estabilidade para os minerais azurite, malaquite, cornetite, libethenite e pseudomalaquite. figura 4 (A) Estrutura do $\mathrm{Ru}\left[9 a_{n} \mathrm{a} \mathrm{S}_{3}(\mathrm{dppz}) \mathrm{Cl}\right]^{+}(\mathrm{dppz}=$ dipiridofenazina, ligando plano, capaz de intercalar entre as bases do ADN); (B) empacotamento do complexo no cristal.
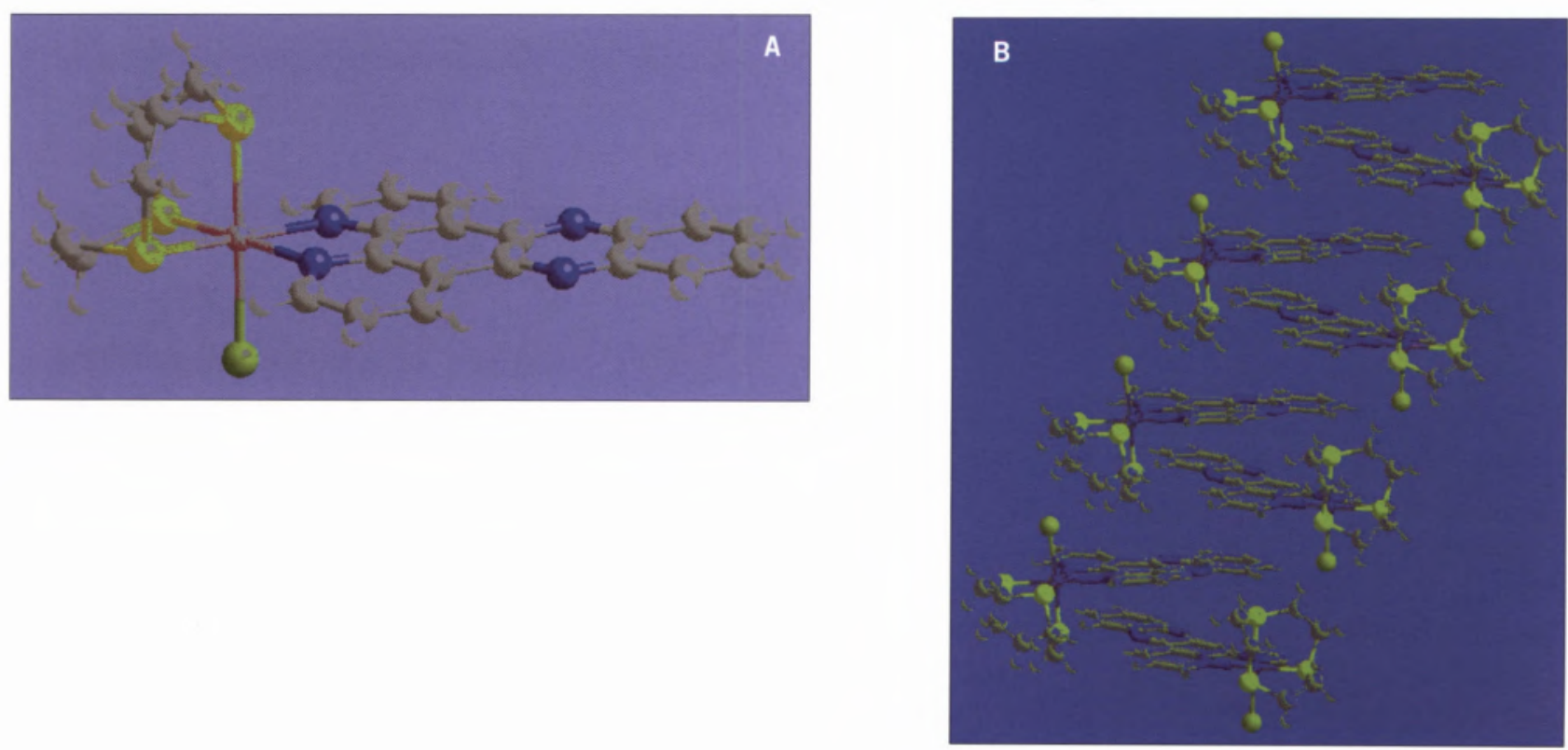
figura 5 Imagem de microscopia electrónica de varrimento de pós de $\mathrm{ZnO}$ obtido a $100^{\circ} \mathrm{C}$ na presença de etilenodiamina (barra $=1 \mu \mathrm{m}$ ).

ta foram particularmente importantes na definição dos trabalhos que vieram a ser desenvolvidos, pois assiste-se aqui à primeira viragem que imprimirá à investigação que decorria uma orientação que teve consequências decisivas nos trabalhos futuros. A linha de investigação do INIC, que inicialmente desenvolvia estudos em Química Inorgânica com uma vertente essencialmente ambiental, foi redireccionada para o estudo da Química de Materiais. Esta aposta vê-se hoje reflectida na participação do grupo de Química Inorgânica no novo Laboratório Associado constituído recentemente.

Podemos notar hoje, ao reler o título dos projectos acima indicados, alguns aspectos curiosamente relevantes para o desenvolvimento do grupo de Química Inorgânica em Aveiro. Em primeiro lugar, encontramos os estudos de complexos de $\mathrm{Cr}$ (III) relacionados com a actividade biológica de metais. Estes estão na origem do trabalho mais tarde apresentado para obtenção de doutoramento, em 1995, por um dos docentes do

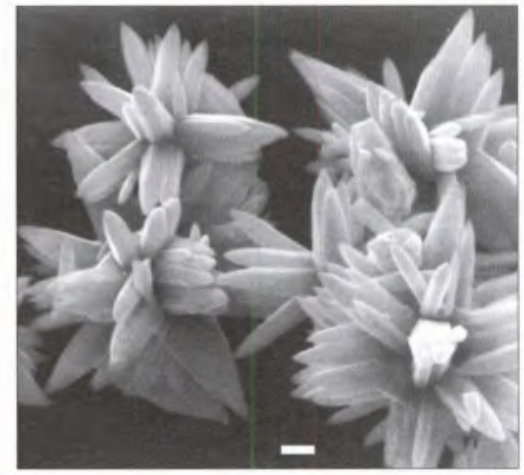

DQUA $\left(\mathrm{TS}^{\star}\right)$, envolvendo já compostos de $\mathrm{Cr}$ (III) e $\mathrm{Cr}(\mathrm{VI})$ e incluindo estudos da interacção de complexos de $\mathrm{Cr}$ (III) com núcleos celulares. Esta linha de trabaIho, que se prolongou até finais dos anos noventa, considerava o estudo de modelos de complexos de $\mathrm{Cr}$ (III) intracelulares e a sua obtenção a partir da redução de $\mathrm{Cr}(\mathrm{VI})$. Se a toxicidade do crómio no estado de oxidação +6 se encontrava já devidamente provada, questionava-se o papel dos compostos de $\mathrm{Cr}$ (III) nos mecanismos de toxicidade deste elemento, dado haver evidência de interacção de $\mathrm{Cr}$ (III) com núcleos de células e com o ADN. Este interesse pela Química Bioinorgânica não foi ainda posto de parte em Aveiro, embora os sistemas objecto de estudo se tenham diversificado e afastado do crómio. Os trabalhos mais recentes incidem em compostos de Ru(II) com grupos polipiridilos (que intercalam no $A D N$ ) e ligandos macrociclos, como o apresentado na figura 4 [7]

Em segundo lugar notamos o aparecimento das palavras "heteropolianiões metálicos" no título dos projectos. Marca o início do trabalho que tem sido desenvolvido em Aveiro na química de polioxometalatos de Mo, W e $\mathrm{Nb}$, em que têm estado directamente envolvidos vários docentes do DQUA. Uma parte significativa da investigação até hoje desenvolvida centra-se nos chamados aniōes do tipo Keggin [8,9]. Estes incluem espécies de fórmula $\left[\mathrm{XM}_{12} \mathrm{O}_{40}\right]^{\mathrm{n}}$, $M=M o, W$ e $X=P, S i, B$, etc., e um conjunto de outros iões que se podem considerar derivados destes, como, por exemplo, os iões substituidos por metais de transição $\left[\mathrm{XW}_{11} \mathrm{M}^{\prime}\left(\mathrm{H}_{2} \mathrm{O}\right) \mathrm{O}_{39}\right]^{\mathrm{m}-}, \mathrm{M}^{\prime}=$ catião da $1^{\text {a }}$ série de transição [10]. Nestes estudos tem-se abordado diversos aspectos da química destes iões, envolvendo a síntese e caracterização de novos compostos com diversos catiões orgânicos, o estudo das suas propriedades e as aplicações em catálise [11] e em ciência de materiais [12] Mais recentemente o interesse na química de polioxometalatos alargou-se a outros tipos de iões, nomeadamente espécies contendo lantanídeos, com vista ao estudo das suas propriedades luminescentes. A aplicação de polioxometalatos em estudos de branqueamento da pasta de papel desenvolvidos no âmbito da investigação em materiais lenhocelulósicos será referido noutro artigo desta revista [13].

No campo da formação de sólidos inorgânicos iniciaram-se trabalhos que reflectiam a conjugação da Ciência de Materiais e da Química que se desenvolvia à época. Este tipo de abordagem, que não era, com certeza, novo, come-

figura 6 Imagem de microscopia electrónica de transmissão de nanofibras de sulfureto de bismuto (barra $=70 \mathrm{~nm}$ )

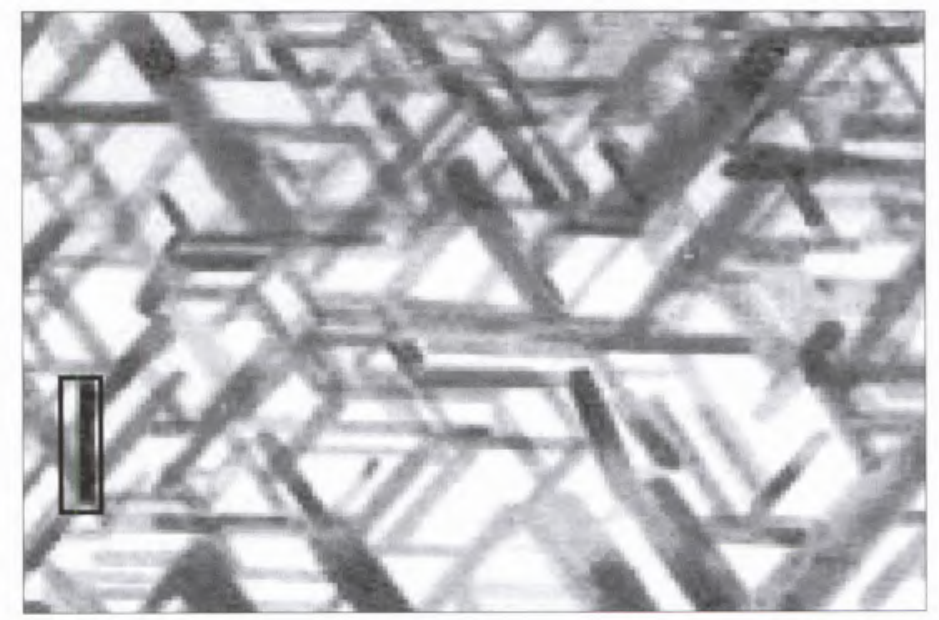




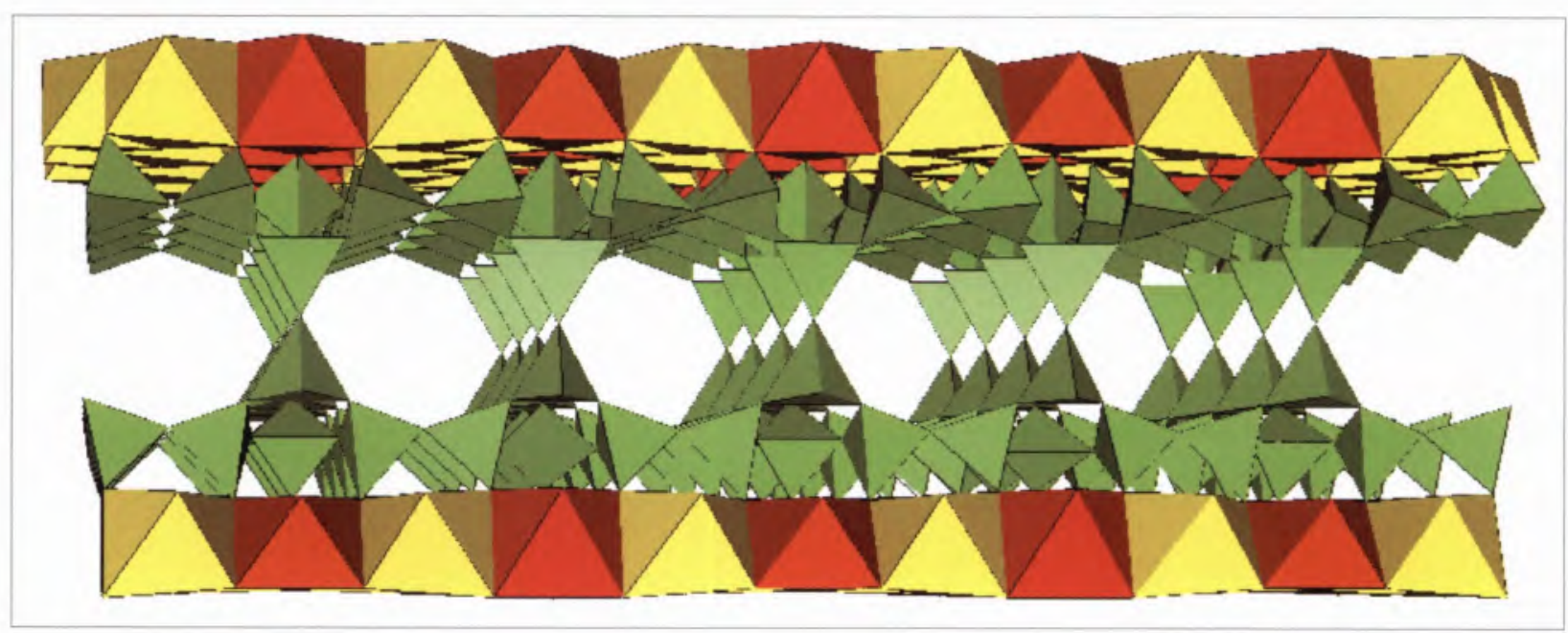

figura 7 AV-9 Silicato de lantanideo (Tb, Eu, Er,...), microporoso e luminescente. Omitem-se os catiōes e as moléculas de água residentes nos poros (verde $\left[\mathrm{SiO}_{4}\right]$, vermelho $\left[\mathrm{LnO}_{6}\right]$, amarelo $\left[\mathrm{NaO}_{6}\right]$ ).

çava a ser reconhecido, tendo-se traduzido no aparecimento de duas importantes publicações periódicas, Chemistry of Materials (1989) e J. of Materials Chemistry (1991). A preparação de pós cerâmicos (em particular, óxidos) por métodos não convencionais era assunto de vários artigos de revisão [14]. Os trabalhos que se iniciaram no DQUA na década de oitenta, em cooperação com o Departamento de Engenharia Cerâmica e do Vidro, debruçaram-se sobre os métodos de síntese controlada de pós cerâmicos. Estudando-se a influência das condições de síntese nas propriedades de óxidos ( $\mathrm{ZnO}$ e $W_{3}$ ), obtidos a partir de precursores e condições diversos, procurava-se influir na forma e tamanho das partículas obtidas (figura 5 [15]). Os estudos de síntese controlada de pós deram origem a duas teses de Mestrado ( $\mathrm{HN}$ e $\mathrm{TT}^{*}$ )

As metodologias estudadas e desenvolvidas nestes primeiros trabalhos e em outros que se Ihe seguiram vieram mais tarde a ter influência numa interessante linha de investigação que se desenvolve actualmente na temática de síntese e estudo de nanopartículas (figura 6 [16]).

\section{A Química Inorgânica e de Materiais em Aveiro}

Por alturas de 1990 ocorreram grandes transformaçōes na investigação científica a nível do País. Vários programas de financiamento contribuiram quer para criar um corpo de estudantes de pósgraduação (o estatuto de bolseiro de investigação data de Dezembro de 1989 [17]) quer para apetrechar as universidades e centros de investigação com novo e actualizado equipamento. Num documento datado de finais de 1991 afirma-se que a Química Inorgânica na UA apresenta um pendor fortemente interdisciplinar, aliando estudos de Química de Coordenação, Bioinorgânica, Ambiental e de Materiais, sendo indicadas as seguintes áreas de estudo:

- Polioxometalatos e óxidos metálicos: precursores em solução, formação e morfologia de sólidos (tungstatos, niobatos, óxidos de zinco e tungsténio), aplicações catalíticas e na produção de materiais avançados.

- Química de coordenação e bioinorgânica: especiação de soluçōes, química de coordenação de crómio e ruténio, biomateriais.

- Desenvolvimento e aplicação de métodos espectroscópicos avançados ao estudo de materiais complexos: RMN de silicatos, aluminossilicatos, aluminofosfatos e de materiais biológicos; estudo de interacções de metais com biopolimeros.

- Química de minerais: sintese, caracterização e estudo termodinâmico da formação de arsenatos, carbonatos e fosfatos.
Identificamos nesta lista uma nova área de intervenção, lançada em Aveiro em consequência do regresso de Inglaterra do hoje Professor João Rocha (JR) (com um doutoramento centrado no estudo da caulinite e materiais relacionados por RMN do estado sólido) e de ter a Universidade adquirido um espectrómetro de RMN multinuclear de $400 \mathrm{MHz}$, totalmente dedicado a RMN do estado sólido, ao abrigo do programa CIENCIA. A preparação e caracterização de novos materiais, incluindo a caracterização de sólidos por RMN, e o estudo das suas aplicações têm hoje uma importância fundamental dentro da investigação realizada em Aveiro.

Os novos projectos desenvolvidos contemplavam a síntese e caracterização de materiais microporosos, como aluminofosfatos ou titanossilicatos. Um número alargado de novos materiais foi aqui preparado, explorando-se os métodos de síntese hidrotérmica e o fenómeno de substituição isomórfica. Um interessante relato do desenvolvimento destes estudos pode encontrar-se nas referências [18] e [19]. Posteriormente este domínio de estudos foi alargado às silicas mesoporosas (com poros de cerca de $50 \AA ̊)$ e, com a colaboração de $\mathrm{IG}^{*}$, à sua derivatização com complexos inorgânicos e organometálicos [20]. 


\section{Os últimos anos}

Em 1994 tem lugar nova reorganização da investigação científica no País com a criação das Unidades de Investigação da JNICT. Sob a direcção de JP, os docentes/investigadores da área da Química Inorgânica do DQUA passaram a integrar o Centro de Química Inorgânica e de Materiais, que compreendia agora diversos domínios de investigação, contando com a colaboração, no seu início, de 14 doutorados entre os quais um especialista em materiais lenhocelulósicos e três doutorados em Bioquímica. Com o passar dos anos, à medida que o número de investigadores aumentava e os projectos de investigação se diversificavam, cresceu o interesse pela Química de Materiais. Esta vertente acentuou-se particularmente a partir de 1999 (a segunda viragem), com a liderança do Centro confiada a JR e veio a culminar com a formação de uma Unidade de Investigação mais alargada que, em 2001, passou a constituir um Laboratório Associado, o CICECO (Centro de Investigação de Materiais Cerâmicos e Compósitos).

Nesta pequena crónica pretendi apresentar o desenvolvimento da investigação em Química Inorgânica na Universidade de Aveiro, desde o seu início até meados dos anos noventa. Estes foram os anos em que a investigação se desenvolveu sob a orientação de Júlio Pedrosa, que imprimiu a sua visão ao conjunto de trabalhos que se referiram e que se empenhou esforçadamente no desenvolvimento que conduziu ao que hoje existe. Foquei essencialmente 0 trabalho feito em Aveiro, muitas vezes em colaboração com outros centros de investigação no País e no estrangeiro, procurando dar uma visão, necessariamente pessoal, de como se criaram as condições que levaram ao que hoje aqui existe. A descrição do que actualmente se faz na área da Química de Materiais não é feita na resenha que aqui se apresenta.

\section{Agradecimentos}

A elaboração deste artigo contou com a colaboração benévola dos docentes do Grupo de Química Inorgânica que acederam a ler o texto, ajudando-me com as suas sugestões e me disponibilizaram informação importante, a quem apresento os meus agradecimentos.

\section{Referências}

[1] J.C. de Melo Neto, Morte e vida Severina e outros poemas em voz alta, Rio de Janeiro, José Olympio, 1983.

[2] M.L.H. Green, in Molybdenum: an outline of its chemistry and uses, E. R. Braithwaite, J. Haber (eds), Elsevier, Amsterdam, 1994.

[3] S.M.O. Quintal, H.I S. Nogueira, H.M. Carapuça, V. Félix e M.G.B. Drew, J. Chem. Soc. Dalton Trans., 2001, 3196-3201.

[4] M. C. F. Magalhães, Geociências; Rev. Univ. Aveiro, 1991, 6, 123-131.

[5] M. C. M. Magalhāes, M. C. M. Silva, Monatsh. Chemie, submetido.

[6] P.A.A.P. Marques, M.C.F.Magalhães; R.N.Correia, Biomaterials, 2003, 24, 15411548.

[7] J. Madureira, T.M. Santos, B. J. Goodfellow, M. Lucena, J. Pedrosa de Jesus, M. G. Santana-Marques; M. G. B. Drew, V. Félix, J. Chem. Soc., Dalton Trans., 2000, 44224431.

[8] M. T. Pope, A. Muller, Angew. Chem., Int. Ed. Engl., 1991, 30, 34-48

[9] J.A.F. Gamelas, I.C.M.S. Santos, M.S.S. Balula, A.M.V. Cavaleiro, Química, Boletim da Sociedade Portuguesa de Química, submetido.

[10] A.M.V. Cavaleiro, J.D. Pedrosa de Jesus, H.I.S. Nogueira, in Metal Clusters in Chemistry, P. Braunstein, L.A. Oro, P.R. Raithbay (Eds), VCH, 1999, vol. 1, p. 444 458.

[11] I.C.M.S. Santos, M.M.Q. Simões, M.M.M.S. P.ereira, R.R.L. Martins, M.G.P.M.S. Neves, J.A.S. Cavaleiro, A.M.V. Cavaleiro, J. Mol. Catal. A, 2003, 195, 253262.

[12] J.A.F. Gamelas, A.M.V. Cavaleiro, E. de Matos Gomes, M. Belsley, E. Herdtweck, Polyhedron, 2002, 21, 2537-2545.
[13] C. P. Neto, D. Evtuguin, Química, Boletim da Sociedade Portuguesa de Química, nesta revista.

[14] D. Segal, Chemical Synthesis of Advanced Ceramic Materials, vol 1 da série Chemistry of Solid State Materials, Ed. A.R. West, H. Baxter; Cambridge University Press, 1989.

[15] T. Trindade, J. Pedrosa de Jesus, P.O'Brien, J. Mater. Chem., 1994, 4, 16111617.

[16] O. C. Monteiro, H.I.S. Nogueira, M. Motevalli, T. Trindade, Chem. Mater., 2001, 13. 2103-2111.

[17] Decreto-lei n 437/89, Diário da República $n^{\circ} 290$, I série, de 19 de Dezembro. Documento de leitura obrigatória. Nele se define, por exemplo, bolseiro de investigação, bolsa de estudo e projecto de investigação.

[18] J. Rocha, V. Félix, M. W. Anderson, Revista Portuguesa de Química, 1996, 35-46.

[19] J. Rocha, M.W. Anderson, Eur. J. Inorg. Chem, 2000, 801-818.

[20] M. Pillinger, I.S. Gonçalves, A. D. Lopes, P. Ferreira, J. Rocha, G. Zhang, Schafer, O. Nuyken, F. Kuhn, Phys. Chem. Chem. Phys., 2002, 4, 696-701.

*Abreviaturas de nomes usadas neste texto:

$$
\begin{aligned}
& \mathrm{CM}=\text { Clara Magalhães } \\
& \mathrm{HN}=\text { Helena Nogueira } \\
& \mathrm{IG}=\text { Isabel Gonçalves } \\
& \mathrm{JP}=\text { Júlio Pedrosa } \\
& \mathrm{JR}=\text { João Rocha } \\
& \mathrm{TS}=\text { Teresa Santos } \\
& \mathrm{TT}=\text { Tito Trindade } \\
& \mathrm{VF}=\text { Vitor Félix } \\
& \mathrm{VG}=\text { Vitor Gil. }
\end{aligned}
$$

